\title{
MicroRNA-124 Suppresses Tumor Cell Proliferation and Invasion by Targeting CD164 Signaling Pathway in Non-Small Cell Lung \\ Cancer
}

\begin{abstract}
MicroRNAs play critical roles in regulating gene expression andvarious cellular processes in human cancer malignant progression. Down-regulated expression of miR-124 gene has been shown to be significantly associated with a poor prognosis in patients with non-smal cell lung cancer (NSCLC) but its biological function and regulatory roles in lung cancer tumorigenesis are largely unknown. In this study, we aimed to determine effects of ectopic expression of miR-124 on tumor cell proliferation, invasion, and induction of apoptosis by DOTAP: Cholesterol nanoparticle-mediated gene transfer and identify its endogenous targets under physiological conditions in NSCLC cells. Over-expression of miR-124 significantly suppresses tumor cell proliferation, colony formation, migration, and induction of apoptosis in H322 and A549 cells. Two endogenous miR-124 targeting sites in the 3'UTR of CD164 mRNA are identified by a stem-loop-array reverse transcription PCR (SLA-RT-PCR) assay in H1299 cells under physiological condition. Ectopic expression of miR-124 induces CDI64mRNA cleavage and down-regulated its gene and protein expression. Our results suggest that miR-124 function as a tumor suppressor miRNA and suppress tumor proliferation and aggression by directly targeting oncogenic CD164 signaling pathway in NSCLC.
\end{abstract}

\section{Introduction}

MicroRNAs (miRNAs) are a class of highly conserved small RNA molecules that function as critical regulators of gene expressionthrough binding to the 3'-untranslated region (3'-UTR) of target mRNAs resulting in either mRNA degradation or translation inhibition [1-3]. MicroRNAs are initially transcribed as long primary transcripts (pri-miRNAs) that undergo sequential processing by the RNase III endonucleases Drosha and Dicer to yield the mature 2023 nucleotide species [4]. Mature miRNAs associate with the RNAinduced silencing complex (RISC) and interact with their binding sites with imperfect complementarity in 3' untranslated regions (UTRs) of target mRNAs. Targeted transcripts subsequently undergo accelerated degradation and reduction of protein production [4,5]. It has been estimated that miRNAs may regulate one third to as many as two thirds of human and mammalian genes and may function as oncogenes or tumor suppressors depending on their targets [6-9]. A growing body of evidence has shown that miRNAs are essential for normal cellular function and development and dysfunction of miRNAs has been linked to many human diseasesand cancer pathogenesis [10].

MicroRNA-124 (miR-124) is one of most frequently dysregulated miRNA genes found in various human cancers such as breast cancer [11,12], lymphoma [13], glioma [14-16], and non-small cell lung

\section{Journal of}

\section{Gene Therapy}

Jing Lin ${ }^{1}$, Kai Xu${ }^{1}$, Jun $W^{i}{ }^{2}$, Amy B. Heimberger ${ }^{2}$, Jack A. Roth ${ }^{1}$ and Lin $\mathrm{Ji}^{\mathbf{1}^{*}}$

${ }^{\prime}$ Department of Thoracic \& Cardiovascular Surgery, University of Texas MD Anderson Cancer Center, USA

${ }^{2}$ Department of Neurosurgery, University of Texas MD Anderson Cancer Center, USA

\section{*Address for Correspondence}

Lin Ji, Department of Thoracic \& Cardiovascular Surgery, University of Texas MD Anderson Cancer Center, Houston, TX, USA, Tel: 7135639143; Fax: 7137928905; E-mail: lj@@mdanderson.org

\section{Submission: 4 January, 2016}

Accepted: 9 February, 2016

Published: 13 February, 2016

Copyright: $\odot 2016$ Lin J, et al. This is an open access article distributed under the Creative Commons Attribution License, which permits unrestricted use, distribution, and reproduction in any medium, provided the original work is properly cited.

Reviewed \& Approved by: Dr. Pablo E. Vivas-Mejia, Department of Biochemistry \& Cancer Center, University of Puerto Rico, USA

cancer (NSCLC) [12,17-19]. Deregulation of miR-124 expression has been shown to be involved in carcinogenesis [20], significantly associated with poor prognosis $[12,18,20,21]$, and function as tumor suppressor inhibiting tumor cell proliferation and metastasis $[19,21]$ in NSCLC. The regulatory roles of miR-124 in many human cancer pathogenesis and malignant progress have been shown to be mediated by targeting and interacting with multiple key genes in tumor suppressing and oncogenic signaling pathways, including STAT3 [12,14,21,22], PIK3K/Akt [21], ROCK1/2 [15,23,24], EZH2 [24,25], NOTCH1 [26], CDK4 [27], FOXQ1 [28] and SPHK1 [29-33]. However, the function and molecular mechanism of miR-124 as well as its endogenous cellular targets have not been fully understood and investigated in lung cancer.

In this study, we constructed various types of plasmid vectors expressing miR-124 precursors to investigate the role of miR-124 as a potential tumor suppressor miRNA in suppression of tumor cell proliferation and progression, and induction of apoptosis and explore its therapeutic potential by DOTAP: Cholesterol nanoparticlemediated miR-124 gene transfer in NSCLC cells $[34,35]$. We also used a novel stem-loop-array reverse transcription PCR (SLA-RT-PCR) assay developed in our laboratory to identify potential endogenous targets specifically interacting with miR-124 to understand the molecular mechanism in miR-124-mediated biological activities and cellular processes in lung cancer cells.

\section{Materials and Methods}

\section{Cell culture}

The human non-small cell lung cancer cell (NSCLC) line H1299, A549 and H322 cells were obtained from ATCC (Manassas, VA) and grown in RPMI 1640 supplemented with 10\% fetal bovine serum and in a humidified incubator with air supply containing $5 \% \mathrm{CO}_{2}$ at $37^{\circ} \mathrm{C}$.

\section{Plasmid construction}

To construct and optimize three human precursor miR-124 (premiR-124) gene expressing plasmids, 86- nucleotides of pre-miR124-1 
Citation: Lin J, Xu K, Wei J, Heimberger AB, Jack AR, et al. MicroRNA-124 Suppresses Tumor Cell Proliferation and Invasion by Targeting CD164 Signaling Pathway in Non-Small Cell Lung Cancer. J Gene Ther 2016; 2(1): 6.

(caggcctctctctccgtgttcacagcggaccttgatttaaatgtccatacaattaaggcacgcggtgaatgccaagaatggggctg), 109-nucleotides of pre-miR124-2 (atcaagattagaggctctgctctccgtgttcacagcggaccttgatttaatgtcatacaattaaggcacgcggtgaatgccaagagcggagcctacggctgcacttgaa), and 87-nucleotides of pre-miR124-3 (tgagggcccctctgcgtgttcacagcggaccttgatttaatgtctatacaattaaggcacgcggtgaatgccaagagaggcgcctcc) DNAs were synthesized from Sigma. Seven plasmids were constructed with the same clinicallyproven backbone consisting of an expression cassette with a CMV promoter and BGH polyA signaling sequences [34] and a combination of three miR-124 precursor sequences in tandem or individually, and they were named as pre-miR124-123, pre-miR124-1, pre-miR124-2, pre-miR124-3, pre-miR124-12, pre-miR124-23, premiR124-13, as illustrated in Figure 1. All constructs were confirmed by DNA sequencing.

\section{DNA transfection}

Cells were plated and cultured overnight, and then transfected with specified expression vectors using DOTAP: Cholesterol (DC)encapsulated plasmid DNA nanoparticles [34]. In brief, $2 \mu \mathrm{L}$ of DC nanoparticles and $2 \mu \mathrm{g}$ of plasmid DNA were mixed, and the mixture was added to each well in a six-well plate and incubated for designated periods of time.

\section{Real-time PCR assays for detecting miRNA}

Total RNA was isolated by using TRIzol reagent (Invitrogen) and additional phenol: Chloroform extraction was performed before ethanol precipitation according to the manufacturer's instruction. Mature miR-124 expression was detected by a quantitative real-time PCR with miR-124-specific primers and Taqman probe (Applied Biosystems). Real-time PCR assays were performed in triplicates and
U6 RNA were used as an internal control.

\section{Apoptosis and cell cycle analysis by flow cytometry using Propidium iodide (PI) DNA staining}

Cells were collected $48 \mathrm{~h}$ after transfection with pre-miR124-1,3 plasmid and the low expression pre-miR124-2 plasmid and untransfected cells were used as negative controls. Cell were fixed in cold $70 \%$ ethanol and stained with $200 \mu \mathrm{l}$ PI $(50 \mu \mathrm{g} / \mathrm{ml})$. Cell cycles were analyzed by flow cytometry.

\section{Colony formation assay}

Cells (single cell suspension) were plated in 6-well plates at a density of 200 cells/well. After $24 \mathrm{~h}$ of incubation, cells were transfected with pre-miR124-1,3 plasmid with pre-miR124-2 and empty plasmid vectors as negative controls. Every three days, the medium was replaced with fresh medium containing $500 \mu \mathrm{g} / \mathrm{ml}$ of G418. After a 10 day treatment, the medium was removed and cell colonies were stained with crystal violet $(0.1 \%$ in $20 \%$ methanol) and counted with a cell counter. Images of stained tumor cell colonies were recorded with a digital camera and numbers and sizes of stained colonies were counted and quantified using imaging analysis software.

\section{Cell migration assay}

Cells were transfected with pre-miR124-1,3 plasmid with premiR124-2 plasmid and empty vector as negative controls. After cells grown into confluent monolayers cells were "wounded" by scratching-off a $1 \mathrm{~mm}$ strip of cells across the well with a standard $200 \mu \mathrm{L}$ pipette tip. The wounded monolayers were washed twice to remove non-adherent cells. Phase-contrast light micrographs were taken immediately after cell removal and after $24 \mathrm{~h}$ of incubation for analysis using Wimasis Image Analysis.
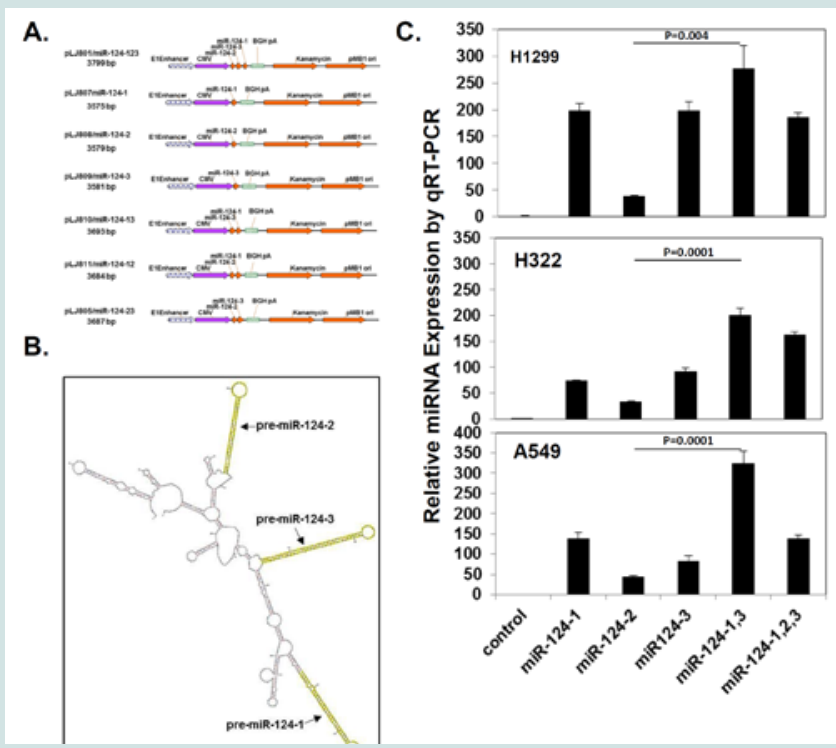

Figure 1: Construction of precursor miR-124 expression plasmids with optimized pre-miR-124 expression and mature miR-124 production. (A) Structures of premiR-124 expression plasmids. Seven plasmids were constructed with the same backbone consisting of an expression cassette with a CMV promoter and BGH polyA signaling sequences and a combination of three miR-124 precursor sequences. (B) The representative secondary structure of a tandem three pre-miR124 precursor miRNA segment with the lowest free-energy was predicted by RNA fold software (Vienna RNA Web Servers). (C) Expression of mature miR-124 in in $\mathrm{H} 1299, \mathrm{H} 322$, and A549 cells transfected with different pre-miR124 constructs by real time qRT-PCR assay (mean \pm SD) ( $n=3$ ). The plasmid vector pre-miR124-1,3 with a combination of pre-miR-124-1 and pre-miR-124-3 produced the highest amount of mature miR-124. Difference between two groups was analyzed by using two-tailed t-test. 
Citation: Lin J, Xu K, Wei J, Heimberger AB, Jack AR, et al. MicroRNA-124 Suppresses Tumor Cell Proliferation and Invasion by Targeting CD164 Signaling Pathway in Non-Small Cell Lung Cancer. J Gene Ther 2016; 2(1): 6.

ISSN: 2381-3326

\section{Western blot assay}

H322 cells were collected $48 \mathrm{~h}$ after transfection with premiR124-1,3 plasmid with pre-miR124-2 plasmid and empty vector as negative controls. Cells were lyzed with Laemini urea buffer. The extract samples were separated by $10 \%$ SDS-PAGE gel and transferred to NC membrane for a conventional western-blotting analysis. The membranes were probed with primary antibodies to CD164 antibody and then incubated with corresponding HRP-conjugated secondary antibody (1: 5000, anti-mouse). Signals were visualize by using an ECL kit (Pierce, IL, USA).

\section{SLA-RT-PCR assay}

RNA samples were briefly treated with $0.04 \mathrm{U} / \mu \mathrm{l}$ of RNAasefree DNAse I. RNA was reversed transcribed using a High Capacity Reverse Transcription kit (Life Technologies) in combination with an array of stem-loop RT-primers. The $20 \mu \mathrm{l}$ of RT reaction contains $50 \mathrm{ng}$ of total RNAs, $5 \times 10^{-12} \mathrm{~mol}$ of SLA-RT primer, $2 \mu \mathrm{l}$ of $10 \mathrm{xRT}$ buffer, $1 \mu \mathrm{l}$ of MultiScribe Reverse Transcriptase, and $0.8 \mu \mathrm{l}$ of 100 mMdNTP. To increase reverse transcription efficiency, a pulsed RT reaction was performed on a DNA Engine Peltier Thermal Cycler (Bio-Rad) with 60 cycles at $18^{\circ} \mathrm{C}$ for 1 min and $37^{\circ} \mathrm{C}$ for 1 second, followed by 60 cycles at $20^{\circ} \mathrm{C}$ for $1 \mathrm{~min}, 37^{\circ} \mathrm{C}$ for 1 second, $37^{\circ} \mathrm{C}$ for $30 \mathrm{~min}, 42^{\circ} \mathrm{C}$ for $20 \mathrm{~min}, 85^{\circ} \mathrm{C}$ for $10 \mathrm{~min}$, and then held at $4{ }^{\circ} \mathrm{C}$. SLA-RT-PCR products were analyzed by agarose gel electrophoresis in $1 \mathrm{x}$ Tr is-borate-EDTA (TBE) buffer containing $89 \mathrm{Mm}$ of Tris Base and $89 \mathrm{mM}$ of Boric Acid.

\section{Statistical analysis}

Quantitative variables with normal distribution were reported as median $\pm \operatorname{SD}(\mathrm{n}=3)$. All assays were with duplicates or triplicates and experiments were repeated at least once. The difference between two treatment groups was analyzed by using two-tailed t-test and $\mathrm{p}$ values $<0.05$ were considered as statistically significant. STATISTICA 12 (StatSoft) software was used for data analysis.

\section{Results \\ Differential expression of miRNA-124 by different pre- miR-124 plasmid constructs}

Three pri-miR-124 genes exist in human genome with different chromosomal locations, expressed as three pre-miR-124 precursors with different sequences, and processed into identical mature miR124 with varied efficiency [36]. There are three predicted precursors of hsa-miR-124, pre-miR124-1 and pre-miR-124-2 encoded in chromosome 8 and pre-miR-124-3 encoded in chromosome 20. To evaluate effects of the pre-miRNA-124 processing and optimize expression plasmid constructs on mature miR-124 production, we constructed various types of plasmid vectors with the same clinicallyproven backbone consisting of an expression cassette with a CMV promoter and BGH polyA signaling sequences and a combination of three miR-124 precursor sequences in tandem or individually (Figures $1 \mathrm{~A}$ and $1 \mathrm{~B}$ ). A significant difference in production of mature miR-124 was observed in H1299, H322 and A549 cells transfected with these pre-miRNA-124 expression plasmids (Figure 1C). Mature miR-124 expression was significantly dependent on the pre-miR-124 sequence and structure. In H1299 cells, miR-124 expression was 80\% less in cells transfected by pre-miR-124-2 compared to pre-miR-124- 1 and pre-miR-124-3. In contrast, the plasmid vector pre-miR124-1,3 with a combination of pre-miR-124-1 and pre-miR-124-3 produced the highest amount of mature miR-124, emphasizing the necessary for optimization of miRNA expression plasmid construction.

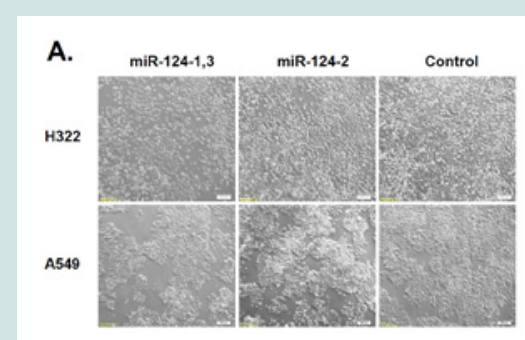

B.

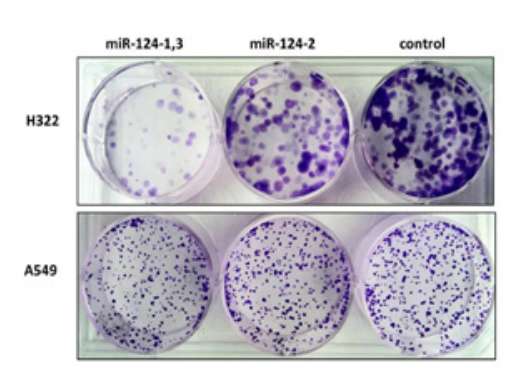

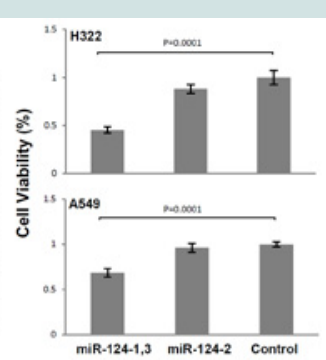

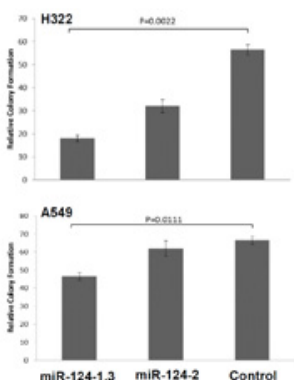

Figure 2: Inhibition of tumor cell proliferations and colony formation by ectopic expression of miR-124 in NSCLC cells. (A) Effects on tumor cell proliferation in H322 and A549 cells by XTT assay (mean \pm SD) $(n=3)$. (B) Effects on tumor cell-induced colony formation in H322 and A549 cells. Left panels showed representative pictures of cell morphologies and proliferation status for XTT assay and colony formation and right panel displayed the quantitative analysis of relative cell viability and colony formation rate in miR-124 expression plasmid transfected cells compared to untransfected controls (mean \pm SD) ( $n=3$ ). Difference between two groups was analyzed by using Two-tailed t-test. 
Citation: Lin J, Xu K, Wei J, Heimberger AB, Jack AR, et al. MicroRNA-124 Suppresses Tumor Cell Proliferation and Invasion by Targeting CD164 Signaling Pathway in Non-Small Cell Lung Cancer. J Gene Ther 2016; 2(1): 6.

ISSN: $2381-3326$

Inhibition of tumor cell proliferation and tumor cellinduced clonogenesis by ectopic expression of miR-124

A significant inhibition on tumor cell proliferation was detected in H322 and A549 cells transfected by miR-124-1,3 plasmid vector compared to those transfected with the low expression miR-1242 plasmid or empty vector control (Figure 2A), with an average of $50 \%$ inhibition rates in $\mathrm{H} 322$ cells and 30\% inhibition rates in A549 cells, respectively. Anchorage-independent growth is an important characteristic of in vitro tumor growth and colony formation assays were performed to examine the effects of miR-124 on in vitro cell growth. Tumor cell-induced colony formation was significantly inhibited in $\mathrm{H} 322$ and A549 cells transfected by miR-124-1,3 (Figure 2B). These results suggest a role of miR-124 as a tumor suppressor miRNA in NSCLC cells.

\section{Identification of CD164 as a direct endogenous target of miR-124 in NSCLC cells}

To identify the endogenous target of miR-124 under physiological condition, we used Targetscan (http://www.targetscan.org/) program to predict the potential targets of miR-124 and found two potential target sites in the 3'UTR of the CD164 mRNA transcript, which are highly conserved in mammals (Figure 3A). To confirm that the CD164 transcript is a direct endogenous target of miR-124, we used a novel sensitive Stem-Loop Array RT-PCR (SLA-RT-PCR) assay developed in our laboratory to detect the potential miR-124-mediated target mRNA cleavage and expression suppression (Figure 3). A series of SLA-RT primers with a 6-nucleotide (nt) probe at their 5 ' termini was designed to match along the miR-124 binding sites on CD164 (Figure
3B). A cleaved 5'-mRNA fragment with its 3' terminal sequence complementarily matched with the probe sequence of an SLA-RT primer was specifically and most efficiently reverse transcribed and its relative abundance was subsequently determined by PCR. The accumulation of a cleaved 5'-mRNA fragment at a specific cleavage site was represented by the relative intensity of each specific SLART-PCR amplicon and resolved on an agarose gel. H1299 cells were transfected with high expression miR-124-1,3 vector and low expression miR-124-2 vector was used as a negative control. MiR124 cleaved 5'-fragments of CD164 mRNA were clearly detected by SLA-RT-PCR as indicated in red box, in H1299 cells transfected with miR-124-1,3 plasmid (Figure 3C). The results from SLA-RTPCR reactions showed elevated amplicon intensities at bases C7-G8 in the seed region after transfected with miR-124-1,3 vector (Figure 3C), which suggest that miR-124 mediated CD164 mRNA cleavage. In addition, down-regulated expression of CD164 protein was also detected in these miR-124 transfectants by Western-blotting assay (Figure 3D). These results confirmed CD164 as an endogenous target of miR-124 in NSCLC cells under physiological condition.

Induction of apoptosis and inhibition of tumor cell migration by miR-124-mediated down-regulation of CD164

To understand the molecular mechanisms in miR-124-mediated tumor suppression and down-regulation of CD164 expression, we determined the induction of apoptosis by ectopic expression of miR124 using FACS analysis with DNA PI staining. A significant induction of apoptosis was detected in H322 and A549 cells transfected with miR-124-1,3, as indicated by an elevated G0/G1 population (Figure
A.

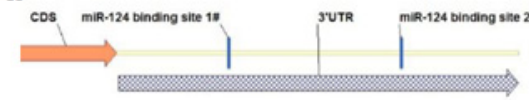

B.
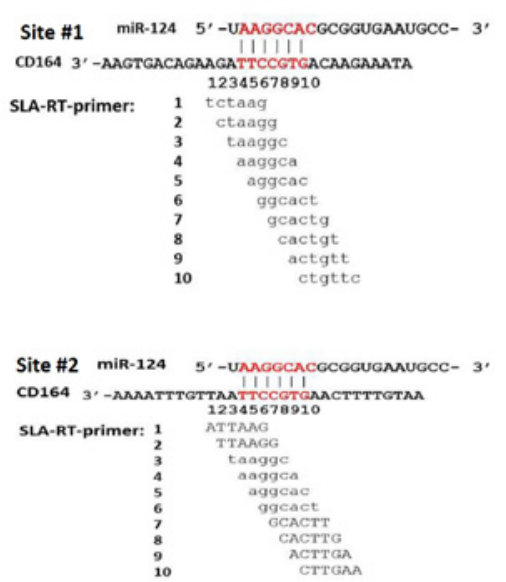

C.
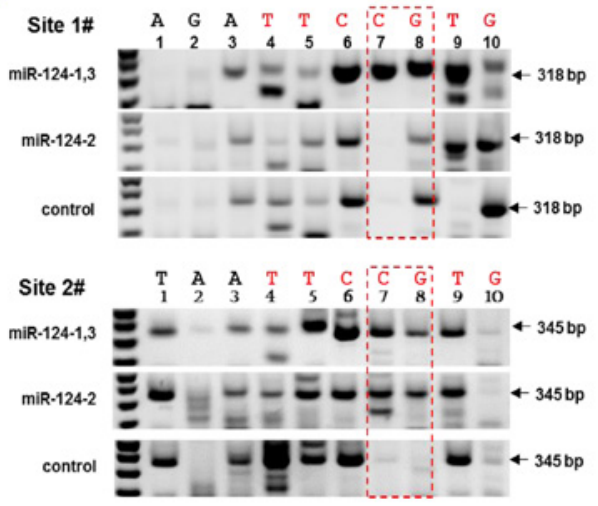

D.

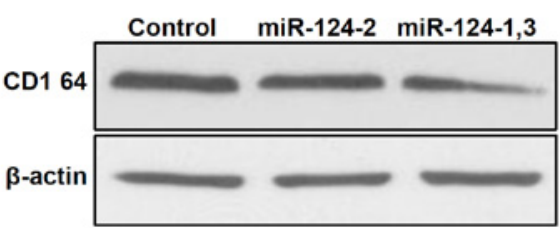

Figure 3: Identification of CD164 as a direct endogenous target of miR-124 in H1299 cells by SLA-RT-PCR analysis. (A) Schematic illustration of two conserved miR-124 binding sites in 3'UTR region of CD164 mRNA. The seed regions of miR-124 and its corresponding recognition sites in the CD164 3'UTR are indicated in red. (B) Ten SLA-RT-PCR primers were designed to detect the miR-124 cleavage sites and cleaved 5'-mRNA fragments based on miR-124-binding site sequences in 3'UTR region of CD164 transcript. (C) Detection of miR-124-mediated cleavage activities on endogenous CD164 mRNA transcripts in H1299 cells transfected with pre-miR-124-1,3 constructs by SLA-RT-PCR and agarose gel electrophoresis analysis. The specific cleavage sites and cleaved CD164 mRNA fragments were indicated in red boxes and by arrows with predicted cleavage fragment sizes. (D) Inhibition of CD164 protein expression by ectopic expression of miR-124 in H1299 cells by Western-blotting analysis. 


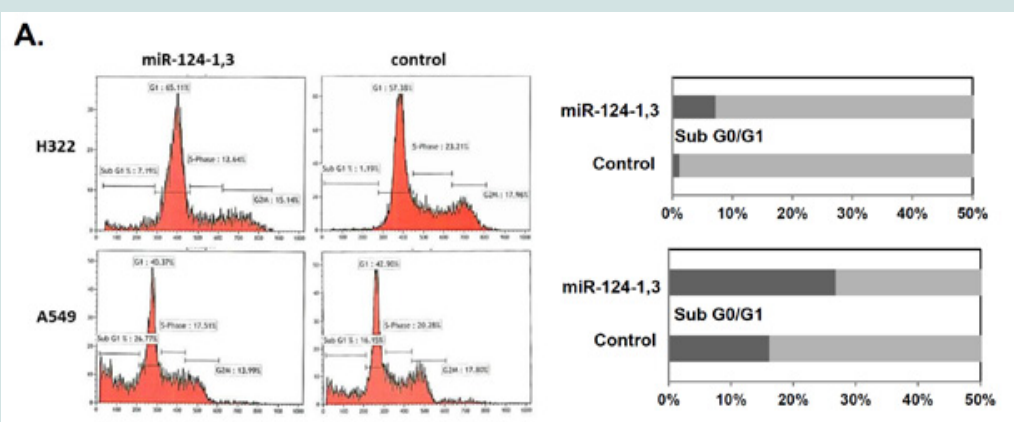

B.
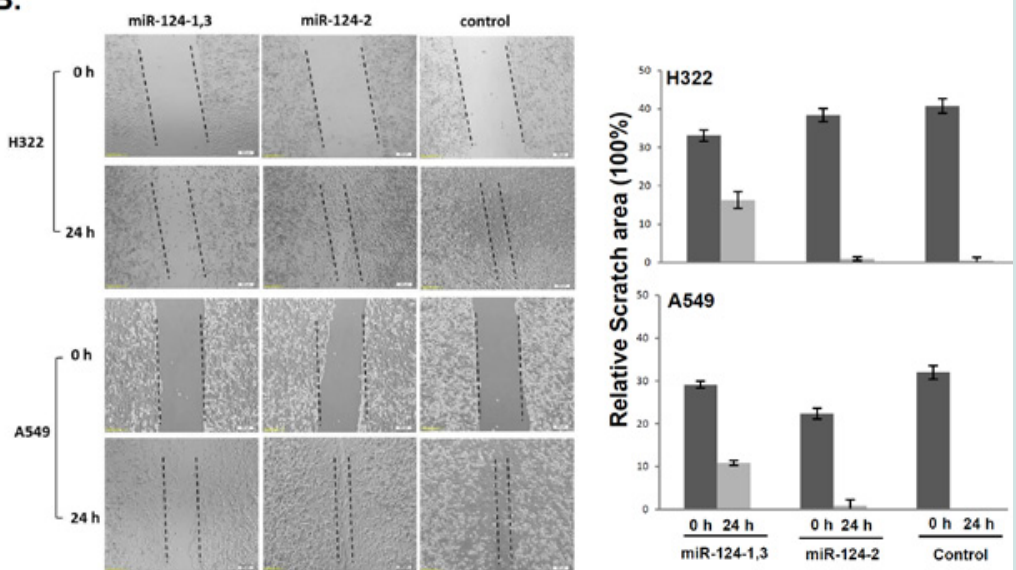

Figure 4: Induction of apoptosis and inhibition of tumor cell migration by ectopic expression of miR-124 in H322 and A549 cells. (A) Induction of Apoptosis by flow cytometry cell cycle analysis using PI DNA staining. Cell populations in subG1/G0 were represented as apoptotic. (B) Inhibition of tumor cell migration by ectopic expression of miR-124 and down-regulation of CD164 expression $24 \mathrm{~h}$ post-transfection with miR-124 plasmids in H322 and A549 cells. The images of cell migration across between scratched gaps on cell monolayers (left panels) and relative scratch area (right panels) were presented, respectively.

4A). Furthermore, to determine biological activity associated with CD164 expression modulation, we used a wound-healing assay to evaluate its effect on tumor cell mobility and migration (Figure 4B). A significant inhibition of tumor cell mobility was observed in $\mathrm{H} 322$ and A549 cells transfected with miR-124-1,3 compared to transfected with miR-124-2 or negative control (Figure 2B).

\section{Discussion}

MicroRNA-based anticancer therapies are being developed to target multiple cancer-driven effector genes in tumor suppressing and oncogenic signaling pathways involved in cell differentiation, proliferation, malignant progression, and survival [37]. Overexpression of miRNAs by introduction of pre-miRNAs plasmids into cells has various advantages compared to synthetic miR mimics. However, pre-miRNAs expression cassettes have not been fully optimized by current studies. Pre-miRNA-124 is encoded in three distinct chromosomal regions but expresses the identical mature form of mature miRNA-124. Because of different secondary structure and flanking sequences in three pre-miR-124 precursorsthe overexpression of pre-miR-124-2 produced the lowest amount of mature miR-124, while pre-miR-124-1,3 plasmid construct containing both the pre-miR-124-1 and pre-miR-124-3 resulted in the highest amount of mature miR-124 production. Our study showed that individual pre-miRNA constructs produce mature miRNAs in different efficiency, emphasizing the importance to optimize miRNA expression constructs for appropriate therapeutic applications of miRNAs. There are two approaches to re-introduce miRNAs into target cells: transfection of synthetic miRNAs (miRNA mimics) and miRNA-expressing vectors. Transfection of synthetic miRNAs is easy and convenient, however, the lack of in vivo efficient delivery and extremely high cost of miRNA mimics synthesis limits their therapeutic use [37]. In contrast, miRNA-expressing vectors have advantages over synthetic miRNA mimics for its unlimited expression of miRNAs and availability of clinically approved DC-nanoparticlemediated systemic administration, which has been developed in our laboratory and successfully used to delivery therapeutic tumor suppressor genes in preclinical and human clinical trials in NSCLC patients [34].

Reintroduction of miR-124 dramatically repressed the proliferation and migration of NSCLC cell in vitro. Moreover, this study has identified CD164 as the direct target of miR-124 in NSCLCs. CD164 is a type I integral transmembrane sialomucin that functions as an adhesion receptor [38]. These findings suggest that miR-124 plays an important role in the migration potential of NSCLCS. In conclusion, we may reasonably speculate that the restoration of miR124 activity, by DOTAP: Cholesterol-pre-miR-124-1,3 nanoparticlemediated miRNA gene transfer may represent an attractive strategy for NSCLC therapy. 
Citation: Lin J, Xu K, Wei J, Heimberger AB, Jack AR, et al. MicroRNA-124 Suppresses Tumor Cell Proliferation and Invasion by Targeting CD164 Signaling Pathway in Non-Small Cell Lung Cancer. J Gene Ther 2016; 2(1): 6.

\section{References}

1. Kato M, Slack FJ (2008) microRNAs: small molecules with big roles - C elegans to human cancer. Biol Cell 100: 71-81.

2. Lim LP, Lau NC, Garrett-Engele P, Grimson A, Schelter JM, et al. (2005) Microarray analysis shows that some microRNAs downregulate large numbers of target mRNAs. Nature 433: 769-773.

3. Calin GA, Croce CM (2006) MicroRNA signatures in human cancers. Nat Rev Cancer 6: 857-866.

4. Lee $Y$, Kim M, Han J, Yeom KH, Lee S, et al. (2004) MicroRNA genes are transcribed by RNA polymerase II. EMBO J 23: 4051-4060.

5. Valencia-Sanchez MA, Liu J, Hannon GJ, Parker R (2006) Control of translation and mRNA degradation by miRNAs and siRNAs. Genes Dev 20 $515-524$

6. Lewis BP, Burge CB, Bartel DP (2005) Conserved seed pairing, often flanked by adenosines, indicates that thousands of human genes are microRNA targets. Cell 120: 15-20.

7. Friedman RC, Farh KK, Burge CB, Bartel DP (2009) Most mammalian mRNAs are conserved targets of microRNAs. Genome Res 19: 92-105.

8. Garzon R, Calin GA, Croce CM (2009) MicroRNAs in cancer. Annu Rev Med 60: $167-179$

9. Garzon R, Fabbri M, Cimmino A, Calin GA, Croce CM (2006) MicroRNA expression and function in cancer. Trends Mol Med 12: 580-587.

10. Kloosterman WP, Plasterk RH (2006) The diverse functions of microRNAs in animal development and disease. Dev Cell 11: 441-450.

11. Feng T, Xu D, Tu C, Li W, Ning Y, et al. (2015) MiR-124 inhibits cell proliferation in breast cancer through downregulation of CDK4. Tumour Biol 36: $5987-5997$.

12. Li X, Yu Z, Li Y, Liu S, Gao C, et al. (2015) The tumor suppressor miR-124 inhibits cell proliferation by targeting STAT3 and functions as a prognostic marker for postoperative NSCLC patients. Int J Oncol 46: 798-808.

13. Jeong D, Kim J, Nam J, Sun H, Lee YH, et al. (2015) MicroRNA-124 links p53 to the NF-kB pathway in B-cell lymphomas. Leukemia 29: 1868-1874.

14. Wei J, Wang F, Kong LY, Xu S, Doucette T, et al. (2013) miR-124 inhibits STAT3 signaling to enhance T cell-mediated immune clearance of glioma. Cancer Res 73: 3913-3926.

15. An L, Liu Y, Wu A, Guan Y (2013) microRNA-124 inhibits migration and invasion by down-regulating ROCK1 in glioma. PLoS One 8: e69478.

16. Cai JJ, Qi ZX, Chen LC, Yao Y, Gong Y, et al. (2016) miR-124 suppresses the migration and invasion of glioma cells in vitro via Capn4. Oncol Rep 35: 284-290.

17. Berghmans T, Ameye L, Willems L, Paesmans M, Mascaux C, et al. (2013) Identification of microRNA-based signatures for response and survival for non-small cell lung cancer treated with cisplatin-vinorelbine A ELCWP prospective study. Lung Cancer 82: 340-345.

18. Guo W, Zhang Y, Zhang Y, Shi Y, Xi J, et al. (2015) Decreased expression of miR-204 in plasma is associated with a poor prognosis in patients with nonsmall cell lung cancer. Int J Mol Med 36: 1720-1726.

19. Sun Y, Ai X, Shen S, Lu S (2015) NF-kB-mediated miR-124 suppresses metastasis of non-small-cell lung cancer by targeting MYO10. Oncotarget 6 : $8244-8254$.

20. Wu S, Shen W, Pan Y, Zhu M, Xie K, et al. (2015) Genetic variations in key microRNAs are associated with the survival of nonsmall cell lung cancer. Medicine (Baltimore) 94: e2084
21. Zhang Y, Li H, Han J, Zhang Y (2015) Down-regulation of microRNA-124 is correlated with tumor metastasis and poor prognosis in patients with lung cancer. Int J Clin Exp Pathol 8: 1967-1972.

22. Li Y, Zhang Z, Liu X, Huang T, He W, et al. (2014) miR-124 functions as a tumor suppressor in the endometrial carcinoma cell line HEC-1B partly by suppressing STAT3. Mol Cell Biochem 388: 219-231.

23. Xu X, Li S, Lin Y, Chen H, Hu Z, et al. (2013) MicroRNA-124-3p inhibits cell migration and invasion in bladder cancer cells by targeting ROCK1. J Trans Med 11: 276.

24. Hu CB, Li QL, Hu JF, Zhang Q, Xie JP, et al. (2014) miR-124 inhibits growth and invasion of gastric cancer by targeting ROCK1. Asian Pac J Cancer Prev 15: $6543-6546$

25. Shi XB, Ma AH, Xue L, Li M, Nguyen HG, et al. (2015) mir-124 and androgen receptor signaling inhibitors repress prostate cancer growth by downregulating androgen receptor splice variants, EZH2, and Src. Cancer Res 75 : 5309-5317.

26. Jiang L, Lin T, Xu C, Hu S, Pan Y, et al. (2016) miR-124 interacts with the Notch1 signalling pathway and has therapeutic potential against gastric cancer. J Cell Mol Med 20: 313-322.

27. Zhang T, Wang J, Zhai X, Li H, Li C, et al. (2014) MiR-124 retards bladde cancer growth by directly targeting CDK4. Acta Biochim Biophys Sin (Shanghai) 46: 1072-1079.

28. Peng XH, Huang HR, Lu J, Liu X, Zhao FP, et al. (2014) MiR-124 suppresses tumor growth and metastasis by targeting Foxq1 in nasopharyngeal carcinoma. Mol Cancer 13: 186.

29. Zheng F, Liao YJ, Cai MY, Liu YH, Liu TH, et al. (2012) The putative tumour suppressor microRNA-124 modulates hepatocellular carcinoma cell aggressiveness by repressing ROCK2 and EZH2. Gut 61: 278-289.

30. Xia J, Wu Z, Yu C, He W, Zheng H, et al. (2012) miR-124 inhibits cell proliferation in gastric cancer through down-regulation of SPHK1. J Patho 227: $470-480$.

31. Lang Q, Ling C (2012) MiR-124 suppresses cell proliferation in hepatocellular carcinoma by targeting PIK3CA. Biochem Biophys Res Commun 426: 247 252.

32. Hunt S, Jones AV, Hinsley EE, Whawell SA, Lambert DW (2011) MicroRNA-124 suppresses oral squamous cell carcinoma motility by targeting ITGB1. FEBS Lett 585: 187-192.

33. Zhang $H$, Wang $Q$, Zhao Q, Di W (2013) MiR-124 inhibits the migration and invasion of ovarian cancer cells by targeting SphK1. J Ovarian Res 6: 84.

34. Lu C, Stewart DJ, Lee JJ, Ji L, Ramesh R, et al. (2012) Phase I clinical trial of systemically administered TUSC2 (FUS1)-nanoparticles mediating functional gene transfer in humans. PLoS One 7: e34833.

35. Lin J, Xu K, Gitanjali J, Roth JA, Ji L (2011) Regulation of tumor suppressor gene FUS1 expression by the untranslated regions of mRNA in human lung cancer cells. Biochem Biophys Res Commun 410: 235-241.

36. Suzhi Z, Liang T, Yuexia P, Lucy L, Xiaoting H, et al. (2015) Gap junctions enhance the antiproliferative effect of microRNA-124-3p in glioblastoma cells. J Cell Physiol 230: 2476-2488.

37. Garzon R, Marcucci G, Croce CM (2010) Targeting microRNAs in cancer rationale, strategies and challenges. Nat Rev Drug Discov 9: 775-789.

38. Tang J, Zhang L, She X, Zhou G, Yu F, et al. (2012) Inhibiting CD164 expression in colon cancer Cell line HCT116 leads to reduced cancer cell proliferation, mobility, and metastasis in vitro and in vivo. Cancer Invest 30 : 380-389.

\section{Acknowledgements}

This work is supported in part by the National Institutes of Health/ National Cancer Institute through a Specialized Program of Research Excellence (SPORE) Grant CA-070907 (J. Minna), and CA176568-02 (Ji, Roth, Wu), a Cancer Prevention and Research Institute of Texas (CPRIT) grant RP130502 (Wu), a MD Anderson's Cancer Center Support Grant CA-016672-Lung Program, DNA Analysis Facility Shared Resource. 